\title{
Involvement of transforming growth factor- $\beta$ in the expression of gicerin, a cell adhesion molecule, in the regeneration of hepatocytes
}

\author{
SEIICHIRO TSUCHIYA ${ }^{1}$, YASUHIRO TSUKAMOTO ${ }^{1}$, EIICHI TAIRA ${ }^{2}$ and JONATHAN LaMARRE ${ }^{3}$ \\ ${ }^{1}$ Laboratory of Veterinary Anatomy, Graduate School of Biology and Environmental Sciences, Osaka Prefecture University, \\ Gakuencho 1-1, Sakai, Osaka 599-8531; ${ }^{2}$ Department of Pharmacology, Iwate Medical School, \\ Uchimaru 19-1, Morioka, Iwate 020-8505, Japan; ${ }^{3}$ Department of Biomedical Sciences, \\ Ontario Veterinary College, University of Guelph, Ontario, N1G 2W1, Canada
}

Received October 27, 2006; Accepted December 5, 2006

\begin{abstract}
Gicerin, an Ig-superfamily cell adhesion molecule, appears transiently in embryonic tissues including those of the nervous, urogenital, respiratory and digestive systems, and it promotes neurite extension, cell migration and epithelialization through its cell adhesive activities. In addition, gicerin also reappears in regenerating tissue after suffering either a traumatic injury or a viral infection. In the present study, we examined the expression pattern of gicerin in the regeneration of hepatocytes. Immunohistochemically, gicerin protein appeared in the regenerating hepatocytes of carbon tetrachloride $\left(\mathrm{CCl}_{4}\right)$-induced acute hepatitis, while it was scarcely expressed in the hepatocytes of normal mouse liver. Real-time PCR revealed the up-regulation of gicerin transcription in the regenerating process of $\mathrm{CCl}_{4}$-induced hepatitis. The expression of transforming growth factor (TGF)- $\beta 1$ was also increased during the regeneration. Furthermore, the gicerin mRNA expression increased during the process of an in vitro hepatocyte regeneration model using mouse primary hepatocytes and hepa 1-6 cells. To note, the mRNA levels of gicerin in these cells were enhanced by the presence of TGF- 1 . Collectively, these findings suggest that TGF- $\$ 1$ may therefore regulate gicerin expression in hepatocytes leading to liver regeneration by cell-cell or cell-ECM interactions.
\end{abstract}

\section{Introduction}

Gicerin is an immunoglobulin superfamily cell adhesion molecule which is purified from chicken smooth muscle

Correspondence to: Dr Yasuhiro Tsukamoto, Laboratory of Veterinary Anatomy, Graduate School of Biology and Environmental Sciences, Osaka Prefecture University, Gakuencho 1-1, Sakai, Osaka 599-8531, Japan

E-mail: ytsuka@vet.osakafu-u.ac.jp

Key words: gicerin, cell adhesion molecule, regeneration, liver, hepatocyte, transforming growth factor- $\beta$
$(1,2)$. Gicerin has a homophilic adhesion property (giceringicerin) as well as a heterophilic adhesive nature in regard to neurite outgrowth factor (NOF), which is an extracellular matrix protein in the laminin family (3). We have identified the gicerin gene from the mouse and rat, and have thus concluded that gicerin is a homologue of human CD146/ MUC18/Mel-CAM (4). Gicerin is expressed during the developmental stages of neural tissues and it therefore promotes cell migration and neurite extension thus forming a neural network $(2,3,5)$. Gicerin is also expressed in other non-neural tissues; in the epithelia of the trachea, kidney and oviduct, gicerin expression is restricted in the developmental period, and it is scarcely found in mature tissues $(6,7)$. In contrast, endothelial cells express gicerin continuously even after maturation. Interestingly, gicerin is overexpressed in some sporadic tumors, and it also promotes binding among tumor cells and the adhesion of tumor cells to ECM, thus leading to tumor progression (8-11).

We previously found that gicerin transiently reappears in wound repair processes in some organs including the trachea, kidney, oviduct and sciatic nerve $(6-8,12)$. Accordingly, gicerin may promote tissue regeneration through its adhesive activities. Various molecules such as cytokines, growth factors and hormones have been reported to participate in wound healing (13). We have shown that nerve growth factor (NGF) can enhance the expression of gicerin in chick dorsal root ganglions, thereby promoting gicerin-mediated neurite extension (14). In addition, forskolin increases the expression of gicerin mRNA in PC12 cells (15). However, the details of the expressional regulation of gicerin remain unclear.

It is well-known that liver regeneration is an excellent model for elucidating the functions of various factors because all liver cells have the ability to proliferate in order to repair hepatic structure after liver damage (16). Nevertheless, hepatocytes are the first cells to proliferate, and most studies give prominence to these cells as they make up $\sim 90 \%$ of the liver's mass and $60 \%$ of the total number of cells. Numerous molecules can regulate the hepatocyte proliferation during liver regeneration (16). One of them, namely transforming growth factor $B$ (TGF- $\beta$ ), is also a soluble molecule which can regulate the hepatocyte proliferation in hepatic 
regeneration. However, the abnormal secretion of TGF- $\beta$ also enhances ECM production, thus leading to the onset of hepatic fibrosis. Therefore, to understand the effect of TGF- $\beta$ on the expression of other molecules may be essential for elucidating the mechanisms of liver regeneration.

In the present study, the effects of TGF- $\beta$ on gicerin expression in regenerating hepatocytes was examined using the experimental models of carbon tetrachloride $\left(\mathrm{CCl}_{4}\right)_{-}$ induced acute hepatitis, and both primary hepatocytes and hepatocyte cell line hepa 1-6. We herein show that TGF- 31 increases gicerin expression in hepatocytes, while also promoting the remodeling of hepatic structure during liver regeneration.

\section{Materials and methods}

Carbon tetrachloride $\left(\mathrm{CCl}_{4}\right)$-induced acute hepatitis model. $\mathrm{CCl}_{4}$ mixed in mineral oil (1:1) was orally administered to adult male ddy mice (SCL Company, Hamamatsu City, Japan) at $0.05 \mathrm{ml} / 10 \mathrm{~g}$ body weight (17). The mice were sacrificed under deep anesthesia with pentobarbital solution on day 1,2,3, and 5 post administration, and then the livers were sampled immediately in order to perform histopathological analyses and RT-PCR. The study protocol was approved by the Animal Care Committee of Osaka Prefecture University, Veterinary School.

Histopathology and immunohistochemistry. The livers were fixed in $10 \%$ buffered formalin and then were embedded in paraffin, cut in $3-\mu \mathrm{m}$ sections and stained with hematoxylin and eosin as a routine procedure. For immunohistochemistry, frozen sections of Zamboni's fixed samples were cut with a cryostat and then were incubated with rabbit polyclonal antibody for gicerin at $37^{\circ} \mathrm{C}$ for $1 \mathrm{~h}(18)$. After washing the sections twice with PBS containing $1 \%$ Triton X-100, they were then incubated with a rhodamine-conjugated secondary antibody (Dako Cytomation, Kyoto, Japan) for $1 \mathrm{~h}$ at $37^{\circ} \mathrm{C}$, and then were examined by fluorescent microscopy after sufficient washing with PBS (7).

Cell cultures of mouse hepatocytes. Fresh liver specimens were removed from ddy mice, and primary hepatocytes were prepared according to the routine procedure (19). The cells were cultured in Wiliams' Medium (Gibco) including 10\% FCS, insulin and dexamethasone 21-phosphate disodium salt (Gibco) for $8 \mathrm{~h}$ and thereafter in the medium without FCS until treatment with TGF- $\beta 1$.

The hepa 1-6 mouse hepatoma cells were propagated in Dulbecco's modified Eagle's medium (DMEM) supplemented with $4.5 \mathrm{~g} / 1$ glucose, $10 \%$ fetal bovine serum (FBS), penicillin $(50$ units $/ \mathrm{ml})$, and streptomycin $(50 \mu \mathrm{g} / \mathrm{ml})$ at $37^{\circ} \mathrm{C}$, $5 \% \mathrm{CO}_{2}$. They were then seeded onto $60-\mathrm{mm}$ culture dishes at a density of $2 \times 10^{6}$ cells.

The above cells were serum-starved for a further $36 \mathrm{~h}$ to synchronize the cultures into quiescence. Next, the cells were cultured in the presence or absence of TGF- $\beta 1$ (Peprotech, London, UK) at various dosages $(1-5 \mathrm{ng} / \mathrm{ml})$. At specified time points, the cells were washed in sterile PBS and scraped directly into TRIzol ${ }^{\mathrm{TM}}$ reagent (Invitrogen). Total RNA was isolated from the cells at each time point according to the recommended procedures and then was subjected to real-time PCR as described below.

Quantitative real-time polymerase chain reaction ( $Q P C R)$. Total RNA was subjected to reverse transcription using the SuperScript II First-Strand Synthesis system (Invitrogen). First-strand cDNAs were amplified using a DNA Engine Opticon system (Bio-Rad). QPCR was performed with iTaq $^{\text {TM }}$ SYBR Green Supermix with ROX (Bio-Rad). The PCR primers used in this study to detect the mRNA of gicerin and TGF- $\beta 1$ are described below: gicerin, forward 5'AAAGTGTGGGTGGAGGTAGA-3', reverse 5'-ATAGTGA AGTGGGGTTGAGG-3'; and TGF-ß1, forward 5'-TATTT GGAGCCTGGACACA-3', reverse 5'-TAGTAGACGATG GGCAGTGG-3'. For the inner control, a set of primers for $18 \mathrm{~S}$ ribosomal RNA was used: forward 5'-ACTCAACACGGGA AACCTC-3', and reverse 5'-TAACCAGACAAATCGCTCC CA-3'. For each gene, PCR was conducted in triplicate with $10 \mu 1$ reaction volumes of $5 \mu 1$ iTaq SYBR Green Supermix with ROX, $0.25 \mu 1(2.5 \mu \mathrm{M})$ of each primer, $3.5 \mu 1$ of nucleasefree water, and $1 \mu \mathrm{l}$ of cDNA. PCR was conducted using the following cycle parameters: 1 cycle at $95^{\circ} \mathrm{C}$ for $15 \mathrm{~min}\left(95^{\circ} \mathrm{C}\right.$ for $10 \mathrm{sec}, 60^{\circ} \mathrm{C}$ for $30 \mathrm{sec}$ and $72^{\circ} \mathrm{C}$ for $\left.30 \mathrm{sec}\right)$ x 40 cycles.

Analysis was carried out using the Opticon Monitor software supplied with the DNA Engine Opticon system. A comparative threshold cycle $(\mathrm{Ct})$ was used to determine the gene expression relative to the non-treated control (calibrator). Hence, the steady-state mRNA levels were expressed as an $\mathrm{n}$-fold difference relative to the calibrator. For each sample, the gicerin or TGF- $\beta 1$ mRNA Ct value was normalized using the formula $\Delta \mathrm{Ct}=\mathrm{Ct}$ sample $-\mathrm{Ct} 18 \mathrm{~s}$. To determine the relative expression levels, the following formula was used: $\Delta \Delta \mathrm{Ct}=\Delta \mathrm{Ct}$ sample $-\Delta \mathrm{Ct}$ calibrator, and the value used to plot relative mRNA expression was calculated using the expression $2-\Delta \Delta \mathrm{Ct}$

\section{Results}

Expression of gicerin protein in the $\mathrm{CCl}_{4}$-induced acute hepatitis model. In the present study, the histopathological changes of the liver inoculated with $\mathrm{CCl}_{4}$ showed processes closely similar to those reported in the literature (20). Focal necrosis of hepatocytes was found in the centrilobular or periportal areas at day 1 post administration, and thereafter a severe regeneration of the hepatocytes occurred on day 2 and day 3 , returning to newly formed hepatic structures by day 5 . Immunohistochemically, gicerin was slightly expressed in the sinusoidal endothelial cells in the normal mouse liver, while it was scarcely found in the hepatocytes (Fig. 1A and D). However, in the $\mathrm{CCl}_{4}$-induced hepatitis model, gicerin also slightly appeared in the hepatocytes on day 3 (Fig. 1B and E). Subsequently, on day 5, the hepatic structures were found to be almost reconstructed, and the expression of gicerin was totally decreased but still observed focally in the new hepatocytes as well as in the sinusoidal endothelium (Fig. 1C and F).

Expression of gicerin and TGF- $\beta 1 \mathrm{mRNA}$ in the $\mathrm{CCl}_{4}$-induced acute hepatitis model. The expressional levels of TGF- $\beta 1$ and gicerin mRNA were analyzed by quantitative real-time PCR in the $\mathrm{CCl}_{4}$-induced hepatitis model. Fig. 2 shows the level of 

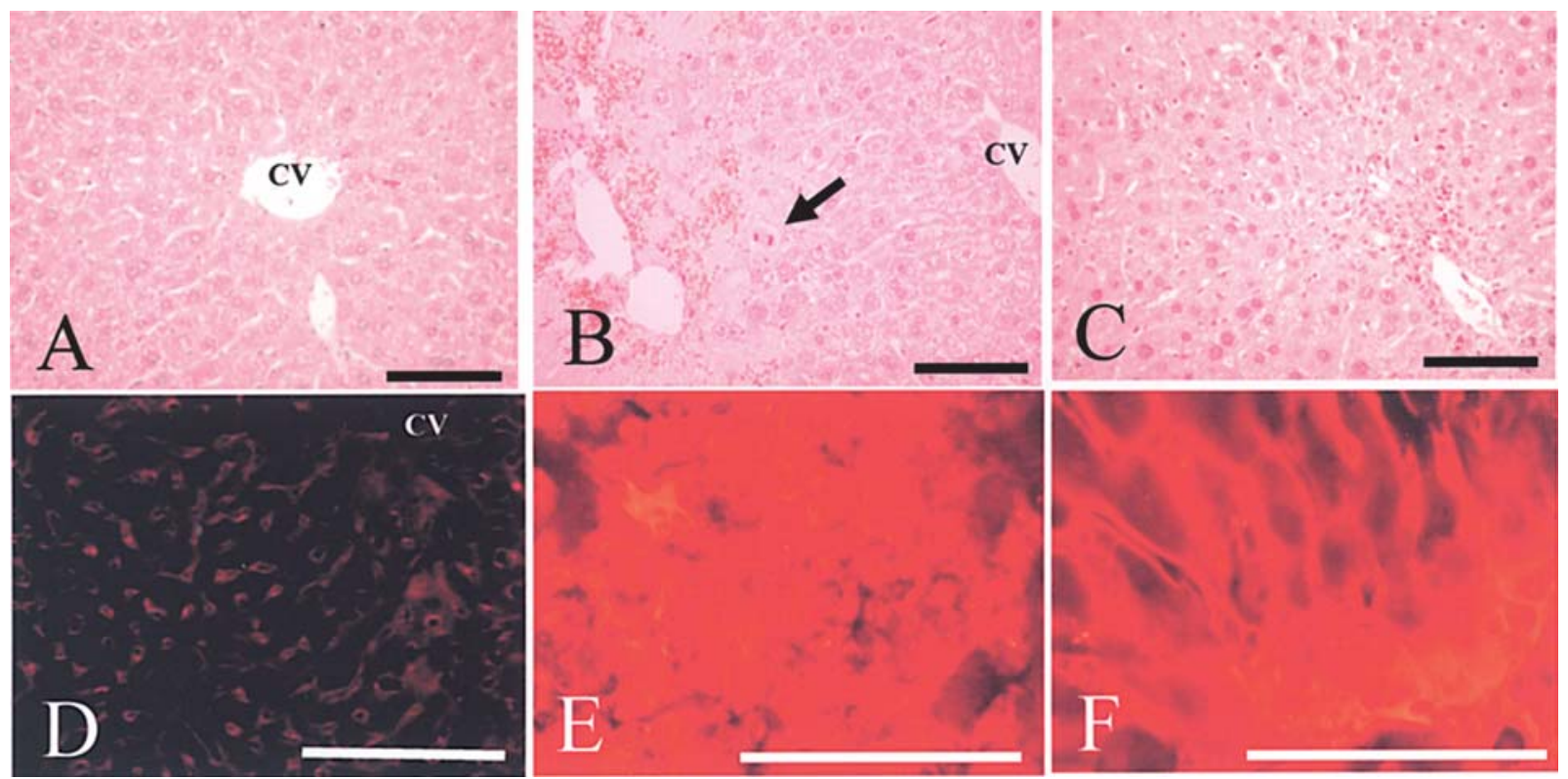

Figure 1. Histopathology (A-C) and immunohistochemistry of gicerin (D-F) in the regeneration of $\mathrm{CCl}_{4}$-induced hepatitis. In the normal mouse liver, gicerin was slightly expressed in the sinusoidal endothelium (A, D). However, gicerin also appears in the hepatocytes in the regenerating areas of $\mathrm{CCl}_{4}$-induced hepatitis at day $3(\mathrm{~B}, \mathrm{E})$. At day 5, when the inflammatory reactions almost ceased and newly-formed hepatic structure appeared, gicerin was still expressed in the hepatocytes as well as in sinusoidal endothelium $(\mathrm{C}, \mathrm{F}) . \mathrm{CV}$, central vein; arrow, mitotic figure in hepatocytes. Bars, $100 \mu \mathrm{m}$.

\section{(A)}

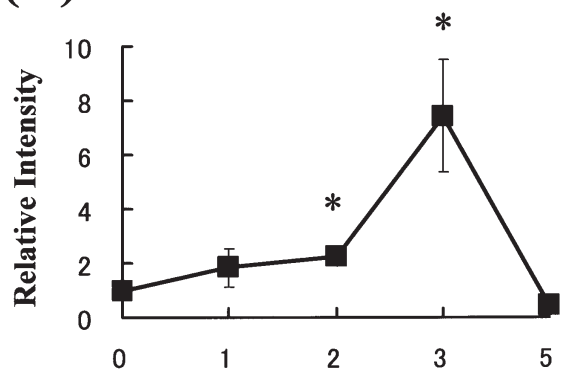

(B)

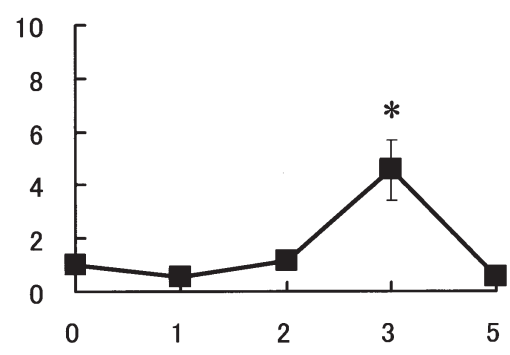

Days after $\mathrm{CCl}_{4}$ administration

Figure 2. Time course expression of gicerin mRNA (A) and TGF- 31 (B) in $\mathrm{CCl}_{4}$-induced hepatitis. The expressional levels were analyzed by real-time RT$\mathrm{PCR}$, and the relative intensity of each time point was quantified with the level of control liver (time 0 ). Values are the mean \pm SE of five mice. *Significant differences from the control liver, $\mathrm{p}<0.05$ (Student's t-test).

both TGF- $\beta 1$ and gicerin mRNA to be elevated in the $\mathrm{CCl}_{4}$ induced hepatitis, while reaching a maximum peak on day 3 and then decreasing to a normal level on day 5. As a result, expression of both genes was transiently up-regulated during in vivo liver regeneration.

Effects of TGF- $\beta 1$ on the expression of gicerin $m R N A$ in mouse primary hepatocytes and hepa 1-6 cells. The primary hepatocytes from the normal mouse liver and hepatocyte cell line hepa 1-6 cells were cultured in serum-free Wiliams' Medium E. These culture systems are thought to be a suitable in vitro hepatocyte regeneration model, since the expressional changes of various factors, including immediate early genes in these culture cell models, showed quite similar actions to those observed during in vivo liver regeneration
$(19,21)$. The time-course expression pattern of gicerin mRNA was examined by quantitative real-time PCR. The mRNA level of gicerin was not significantly elevated in both primary hepatocytes and hepa 1-6 cells at all time points after seeding (Fig. 3). Since the synchronized enhancement of gicerin and TGF- $\beta 1$ was found in the $\mathrm{CCl}_{4}$-induced acute hepatitis model, the effect of TGF- $\beta 1$ on the expression of gicerin was examined using these culture cells. In both cells, the expressional levels of gicerin mRNA significantly increased with the addition of TGF- $\beta 1$ in comparison to the non-serum control culture medium (Fig. 3). This increase in gicerin mRNA was found at $32 \mathrm{~h}$ in primary hepatocytes and at $24 \mathrm{~h}$ in hepa 1-6 cells. In addition, we also found a dosedependent increase in the gicerin mRNA expression with TGF-ß1 volumes of 1-5 ng/ml (Fig. 4). 

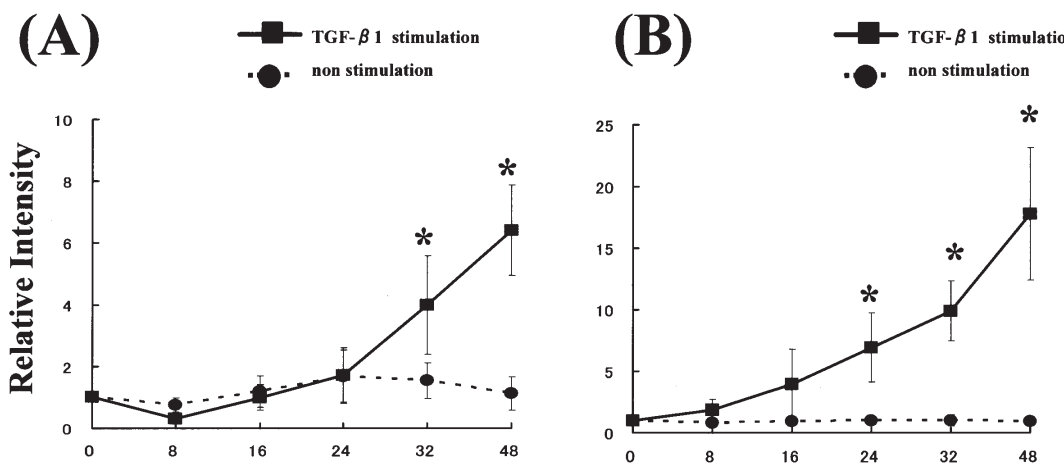

\section{Hours after TGF- $\beta 1$ stimulation}

Figure 3. Time course expression of gicerin mRNA in the mouse primary hepatocytes (A) and hepa 1-6 cells (B) after stimulation with TGF- 31 . The expressional levels were analyzed by RT-PCR, and the relative intensity of each time point was quantified with the level of time 0 of each cell. Values are the mean \pm SE of five experiments. *Significant differences from the non-stimulations at the same time points, $\mathrm{p}<0.05$ (Student's t-test).

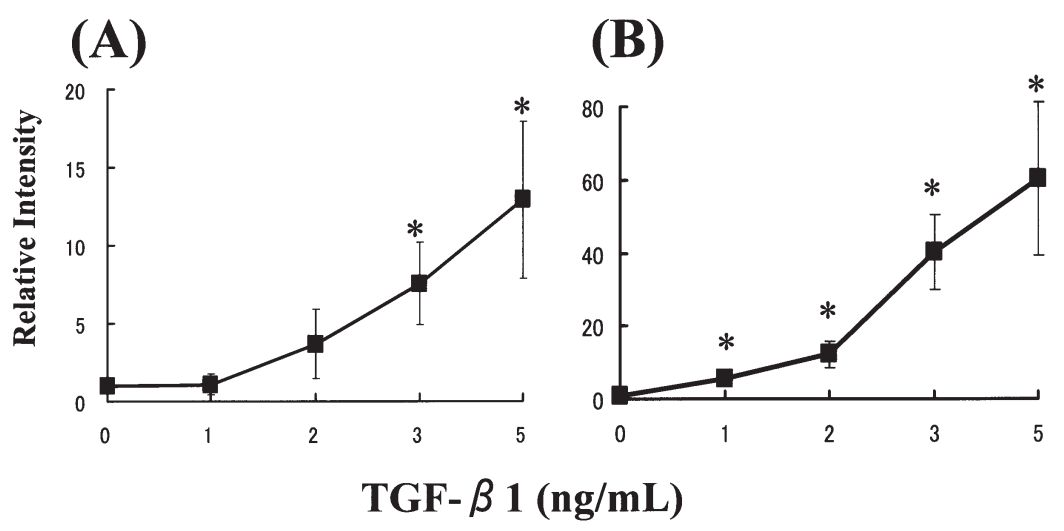

Figure 4. Dose-dependent expression of gicerin mRNA in the mouse primary hepatocytes (A) and hepa 1-6 cells (B) after stimulation with various dosages of TGF-ß1 (1-5 ng/ml). The expressional levels were analyzed by RT-PCR, and the relative intensity of each time point was quantified with the level of time 0 of each cell. Values are the mean \pm SE of five experiments. *Significant differences from time $0, p<0.05$ (Student's t-test).

\section{Discussion}

Like most other cell adhesion molecules in the Ig-superfamily, gicerin has cell adhesive activities with its ligands $(8-11,22)$. We have previously reported that gicerin in regenerating cells might participate in the reconstruction of injured tissues through its cell adhesion properties; namely, cell-cell connections in the remodeling epithelium are promoted by gicerin-gicerin interaction, while cell-ECM binding is also enhanced by gicerin-NOF interaction (7). In addition, gicerin can promote the axon-axon interactions in the regenerating peripheral nerve after a clamp injury of the sciatic nerve (12).

Hepatocyte regeneration proceeds along a sequence of three main phases: a priming phase rendering hepatocytes in a state of replicative competence; a proliferation phase where the expansion of the entire hepatocyte population takes place; and a termination phase where cell proliferation is suppressed to terminate regeneration (16). Various factors have been reported to regulate liver regeneration $(16,23)$. It is thought that subsequent cell-cell and/or cell-ECM interactions in the termination phase are therefore essential phenomena for successful redesign and remodeling of hepatic structures. A major factor involved in the termination response comprises TGF- $\beta$. TGF- $\beta$ is produced by hepatocytes and non-parenchymal cells during liver regeneration, and it terminates the hepatocellular proliferation while enhancing the ECM synthesis leading to the remodeling of hepatic tissues. The critical role of TGF- $B$ in hepatocyte regeneration has been reported; TGF- $\beta$ down-regulated the transcription of genes for DNA synthesis and then inhibited hepatocyte growth (24). This indicates that TGF- $\beta$ may play a potential role in inhibiting the growth of an excessive population of hepatocytes, thus leading to the expansion phase to eventually terminate the regeneration which is also responsible for normal hepatic cord formation and resinusoidalization.

We herein focused on the role of TGF- $\beta$ and gicerin in the remodeling of hepatic structure during liver regeneration processes. In the present study, the expression of gicerin in hepatocytes transiently increased in the regeneration processes of a $\mathrm{CCl}_{4}$-induced hepatitis model. On days 3 and 5 post $\mathrm{CCl}_{4}$ administration, we found a strong expression of gicerin in the hepatocytes in the regenerating areas based on immunohistochemical observations. Although we did not determine the TGF- $\$ 1$ producing cells in the present study, various components of hepatic cells including hepatocytes, 
lipocytes, endothelial cells and Kupffer cells have been reported to secrete TGF- $\beta 1$ during the regeneration of $\mathrm{CCl}_{4}{ }^{-}$ induced hepatitis (24). Accordingly, the appearance of gicerin in hepatocytes might therefore promote the remodeling of hepatic tissue, by such actions as hepatocyte-hepatocyte interactions, and hepatocyte-perisinusoidal ECM through gicerin's adhesive activities.

To note, both the expression of TGF- $B 1$ and gicerin mRNA were transiently increased in the regenerating process of the $\mathrm{CCl}_{4}$-induced hepatitis model. Similar to other reports describing TGF- $\beta$ mRNA in $\mathrm{CCl}_{4}$ hepatitis (25), we found a transient increase of TGF- $\beta 1$ mRNA on day 3 post $\mathrm{CCl}_{4}$ administration. Based on these findings, we therefore speculate that TGF- $\beta 1$ regulates the gicerin expression in hepatocytes, while also contributing to the remodeling of hepatic structures after liver injury.

To support this paradigm, we next confirmed the potential effect of TGF- $\beta 1$ on gicerin expression in hepatocytes by performing an in vitro analysis. Either primary hepatocytes or hepa 1-6 cells are a suitable model for future studies of various transcriptional genes on liver regeneration $(19,21)$. Notably, the mRNA level of gicerin in both culture cells increased during the time course after seeding onto the dish, thus suggesting that gicerin transcription is regulated by other factors. One novel and significant finding of this study is that TGF- $\beta 1$ increased the expression of gicerin mRNA in either primary mouse hepatocytes or hepa 1-6 cells . Accordingly, the following hypothetical processes were thus suggested: i) in the termination phase of liver regeneration, TGF- $\beta 1$ is secreted from non-parenchymal cells while also enhancing the expression of gicerin in hepatocytes but inhibiting their proliferation, ii) gicerin in the hepatocytes promotes the interactions among hepatocytes and hepatocyteperisinusoidal ECM, and iii) the remodeling of the hepatic cords and lobules both progress successfully through these cell-cell and cell-ECM interactions by gicerin.

It is well-known that the action of TGF- $\beta 1$ is mediated by its receptor Smad protein thus serving as intracellular signals in a subsequent pathway $(26,27)$. Although the promoter region of the gicerin gene has some functional sequences such as Sp1, AP-2 and CRE, the potential factors which interact directly with these sites and regulate the gicerin transcription still remain to be clarified. Therefore, further studies are needed to elucidate the exact interaction of the potential molecules in the intracellular pathways by TGF- $\beta$ stimulation.

\section{Acknowledgements}

This study was supported in part by a Research Fellowship of the Japan Society for the Promotion of Science for Young Scientists A (no. 17688013).

\section{References}

1. Taira E, Takaha $\mathrm{N}$ and Miki $\mathrm{N}$ : Extracellular matrix proteins with neurite promoting activity and their receptors. Neurosci Res 17: 1-8, 1993.

2. Taira E, Takaha N, Taniura H, Kim CH and Miki N: Molecular cloning and functional expression of gicerin, a novel cell adhesion molecule that binds to neurite outgrowth factor. Neuron 12: 861-872, 1994.
3. Taira E, Tsukamoto Y, Kohama K, Maeda M, Kiyama H and Miki N: Expression and involvement of gicerin, a cell adhesion molecule, in the development of chick optic tectum. J Neurochem 88: 891-899, 2004

4. Taira E, Kohama K, Tsukamoto Y, Okumura S and Miki N: Characterization of Gicerin/MUC18/CD146 in the rat nervous system. J Cell Physiol 198: 377-387, 2004.

5. Tsukamoto Y, Taira E, Miki N and Sasaki F: The role of gicerin, a novel cell adhesion molecule, in development, regeneration and neoplasia. Histol Histopathol 16: 563-571, 2001.

6. Takaha N, Taira E, Taniura H, Tsukamoto Y, Matsumoto T, Kotani T, Sakuma S and Miki N: Expression of gicerin in development, oncogenesis and regeneration of the chick kidney. Differentiation 58: 313-320, 1995.

7. Tsukamoto Y, Taira E, Kotani T, Yamate J, Wada S, Takaha N and Sakuma S: Involvement of gicerin, a cell adhesion molecule, in tracheal development and regeneration. Cell Growth Differ 7: 1761-1767, 1996.

8. Tsukamoto Y, Taira E, Kajinuma K, Yamate J, Kotani T, Amin H, Kohama K, Sakuma S, Miki N and Sasaki F: Involvement of gicerin, a cell adhesion molecule, in development and regeneration of oviduct and metastasis of oviductal adenocarcinomas of the chicken. Exp Cell Res 247: 329-338, 1999.

9. Tsukamoto Y, Egawa M, Hiroi S, Miki N, Sasaki F and Taira E: Gicerin, an Ig-superfamily cell adhesion molecule, promotes the invasive and metastatic activities of a mouse fibroblast cell line. J Cell Physiol 197: 103-109, 2003.

10. Tsuchiya S, Tsukamoto Y, Furuya M, Hiroi S, Sasaki F and Taira E: Gicerin, a cell adhesion molecule, promotes the metastasis of lymphoma cells of the chicken. Cell Tissue Res 314: 389-397, 2003

11. Tsukamoto Y, Sakaiuchi T, Hiroi S, Furuya M, Tsuchiya S, Sasaki F, Miki N and Taira E: Expression of gicerin enhances the invasive and metastatic activities of a mouse mammary carcinoma cell line. Int J Oncol 23: 1671-1677, 2003.

12. Hiroi S, Tsukamoto Y, Sasaki F, Miki N and Taira E: Involvement of gicerin, a cell adhesion molecule, in development and regeneration of chick sciatic nerve. FEBS Lett 554: 311-314, 2003.

13. Kim WJ: Cellular signaling in tissue regeneration. Yonsei Med J 41: 692-703, 2000.

14. Hiroi S, Taira E, Ogawa K and Tsukamoto Y: Neurite extension of DRG neurons by gicerin expression is enhanced by nerve growth factor. Int J Mol Med 16: 1009-1014, 2005.

15. Kohama K, Tsukamoto Y, Furuya M, Okamura K, Tanaka H, Miki N and Taira E: Molecular cloning and analysis of the mouse gicerin gene. Neurochem Int 46: 465-470, 2005.

16. Michalopoulos GK and DeFrances MC: Liver regeneration. Science 276: 60-66, 1997.

17. LeSage GD, Glaser SS, Marucci L, Benedetti A, Phinizy JL, Rodgers R, Caligiuri A, Papa E, Tretjak Z, Jezequel AM, Holcomb LA and Alpini G: Acute carbon tetrachloride feeding induces damage of large but not small cholangiocytes from BDL rat liver. Am J Physiol 276: 1289-1301, 1999.

18. Tsukamoto Y, Kotani T, Hiroi S, Egawa M, Ogawa K, Sasaki F and Taira E: Expression and adhesive ability of gicerin, a cell adhesion molecule, in the pock lesions of chorioallantoic membranes infected with an avian poxvirus. Can J Vet Res 65 : 248-253, 2001.

19. Benn SJ, Allan A, Laithwaite JE, Tsukamoto Y, Yamate J, Kirby $\mathrm{G}$ and LaMarre $\mathrm{J}$ : Effect of extracellular matrix on gene expression and mRNA stability in primary rat hepatocytes. J Toxicol Pathol 11: 219-227, 1999.

20. Yu C, Wang F, Jin C, Wu X, Chan WK and McKeehan W: Increased carbon tetrachloride-induced liver injury and fibrosis in FGFR4-deficient mice. Am J Pathol 161: 2003-2010, 2002.

21. Allan AL, Albanese C, Pestell RG and LaMarre J: Activating transcription factor 3 induces DNA synthesis and expression of cyclin D1 in hepatocytes. J Biol Chem 276: 27272-27280, 2001.

22. Tsukamoto $Y$, Namikawa $T$, Tatesaki R, Kotani T and Tanaka H: Expression and adhesive activity of SC1, an Ig superfamily cell adhesion molecule, in sporadic nephroblastomas of chicken. Oncol Rep 15: 137-141, 2006.

23. Wang JY, Chiu JH, Tsai TH, Tsou AP, Hu CP, Chi CW, Yeh SF, Lui WY, Wu CW and Chou CK: Gene expression profiling predicts liver responses to a herbal remedy after partial hepatectomy in mice. Int J Mol Med 16: 221-231, 2005. 
24. Bissell DM, Wang SS, Jarnagin WR and Roll FJ: Cell-specific expression of transforming growth factor-beta in rat liver. Evidence for autocrine regulation of hepatocyte proliferation. J Clin Invest 96: 447-455, 1995.

25. Yoshino R, Miura K, Segawa D, Hirai Y, Goto T, Ohshima S, Mikami K, Yoneyama K, Shibuya T, Watanabe D, Kataoka E, Takeuchi S, Endoh A, Sato W and Watanabe S: Epimorphin expression and stellate cell status in mouse liver injury. Hepatol Res 34: 238-249, 2006.
26. Massague J: TGF-ß signal transduction. Annu Rev Biochem 67: 753-791, 1998.

27. Attisano L and Tuen Lee-Hoeflich S: The Smads. Genome Biol 2: 3010.1-3010.8, 2001. 